\title{
FALL PREVENTION AMONG OLDER ADULTS: CASE REPORTS EXEMPLIFYING THE VALUE OF INCORPORATING LUMBAR STABILIZATION TRAINING DURING BALANCE EXERCISES
}

\begin{abstract}
Background: Older adults are at risk of falling each year. Fall injuries results in many health care expenses and disabilities, yet non-western countries lack the infra-structure and resources for prevention programs. Balance exercises have been found to be a cost effective evidence-based intervention in treating and preventing falls among older adults in western countries.

Purpose: The aim of this report was to show that lumbar stabilization exercises are not only a beneficial addition to a balance program for the prevention and treatment of falls in older adults, but to demonstrate that these exercise can more rapidly improve the functional status of older adults, limiting healthcare costs.
\end{abstract}

Case description: Two high functional older adults with a history of falls presented with poor balance and fear of falling. Both patients received the same balance exercise regime however lumbar stabilization exercises were added to one of the patient's exercise programs. Gait speed, lower extremity strength and balance were assessed with the Balance Evaluation systems test (BESTest), figure-of-eight, four-step-square (FSST), five-time-sit-to-stand tests (5TSTS) after two weeks and four weeks of treatment.

Outcomes. All the outcome measures showed statistically significant improvements. Greater improvements in vertical stability limits (14\%), gait speed (9\%), stability during gait (20\%) and five-time-sit-to-stand test were seen with the addition of lumbar stabilization exercises.

Discussion. The addition of lumbar stabilization exercises during balance training is of value to improve gait speed, balance testing scores in stability in gait and vertical stability limits.

KEY WORDS: BALANCE EXERCISES, CORE STABILIZATION, FALL PREVENTION, LUMBAR STABILIZATION EXERCISES, OLDER ADULTS, PERTURBATION.

\section{BACKGROUND}

One third of United States' older adult population has a risk of falling each year with the highest rate among 75 year olds. Healthcare cost escalated above \$19 billion during 2000 according to the Center of Disease Control and Prevention. In non-western societies

\section{Correspondence Author:}

Dr Petronella van der Merwe

Dr. Petro van der Merwe Physiotherapy

P.O. Box 684, Rivercresent,

Witbank, South Africa

Email: levouyvdm@mweb.co.za like South Africa $18 \%$ of the older adult population were counted as disabled in 2001. Three out of five of these older adults were hospitalized with fall risks due to frailty (Statistics South Africa 2001). Fall prevention and care however is neglected due to South African legislature which only allows $2 \%$ of the older population access to state-supported institutional facilities (Czerniewicz et al 2004).

Balance training is a cost effective fall prevention intervention in western societies (Madureira et al 2007). Balance challenged in three ways: reducing base of support, moving center of gravity and controlling body position are the most effective form of evidencebased interventions. Standing exercises with reduced upper limb support have also been found to improve static and dynamic balance and decrease the risk of falling (Sherrington et al 2008). Additional lower extremity exercises improved center of pressure velocity, sensory interaction during balance, directional control, lower extremity strength and stability limits (Burke et al 2010). Evidence-based alternative balance training like Tai chi improves functional balance, directional control and walking velocity during gait, and 
postural stability (Li et al 2010). Postural stabilization training is also listed in the Guide to Physical Therapy Practice's Pattern 5A, as an evidence-based fall prevention intervention. Postural stability especially plays an important role in controlling and improving changes in spinal load transfer patterns during perturbation (Muthukrishnan et al 2009).

Postural control exercises help to develop more efficient postural control strategies (Nagai et al 2012). Muscle weakness, a major fall risk factor, causes postural instability (Orr 2010). Dynamic lumbar stabilization training improves weight bearing distribution, gait and quality of life (Kaya et al 2012). Lumbar strengthening in functional positions are similar to regular balance exercises except that the transverse abdominus is constantly activated with the use of implicit motor learning techniques such as a biofeedback device and manual muscle activation (O'Sullivan 2000). The aim of this study was to demonstrate the value of additional lumbar stabilization exercises during fall prevention balance training to lower fall risk.

\section{CASE DESCRIPTION}

\section{Medical history}

Two physically independent patients age 71 years (Patient A) and 74 years (Patient B) presented with a history of falling, fear of falling and instability during environmental fluctuation and pivot movements. Both patients suffered with osteoarthritis and hypertension. Patient A was medicated with Ziac $10 \mathrm{mg} /$ day, Fedaloc SR $30 \mathrm{mg} /$ day and Patient B with Lomanor 50mg/day. Patient A and B inconsistently reported muscle spasm $2 / 10$ based on the analogue pain scale in the thoracic and lumbar area.

\section{Systems review}

Thorough evaluations are recommended according to the American and British geriatric society clinical practice guidelines 2011 for prevention of falls among older adults. This includes physical examinations of gait, balance and lower extremity muscle strength levels and neurological assessments which evaluate cognitive function, lower extremity peripheral nerves, proprioception and reflexes. Examination of the feet for deformities and pain is recommended due to its association with impaired balance and fall risk. The International Classification of Functioning, Disability, and Health (ICF) model was applied with the assessment of the cardiovascular status due to hypertension's' effect on fall risks.

Both patients' exhibited sway-back postures and pain free full lumbar spine range of motion. Upper and lower extremity muscle strength and range of motion were within normal limits as measured by the Kendall's manual muscle test, "back-scratch" and "chair-sit-and-reach" tests. The neurological screening of sensation, upperand lower extremity myotomes and reflexes presented normal while the active-straight-leg-raise test in both patients revealed weakness of transverse abdominus. The integumentary and foot screening showed bruised big toes of Patient A, varicose veins of Patient B and bilateral feet hammer toe formation of both patients. Vital signs were tested before and after the functional assessment tests (Table 1).

\section{FUNCTIONAL ASSESMENT TESTS}

The Balance Evaluation systems test (BESTest) was used due to its' high validity and reliability in differentiating between biomechanical constraints, stability limits, anticipatory postural adjustments, postural responses, sensory orientation and gait stability. The BESTest and gait speed have high sensitivity and validity in identifying fallers (Leddy et al 2011, Brach et al 2008). Greater step length and stance

Table 1: Cardiovascular screening and vital signs assessment before and after the Balance evaluation systems test (BESTest).

\begin{tabular}{|c|c|c|c|c|}
\hline Vital signs & \multicolumn{2}{|c|}{ Patient A } & \multicolumn{2}{c|}{ Patient B } \\
\hline Rest & $\begin{array}{c}\text { After } \\
\text { BESTest }\end{array}$ & Rest & $\begin{array}{c}\text { After } \\
\text { BESTest }\end{array}$ \\
\hline Heart rate & 80 & 99 & 66 & 71 \\
\hline Blood pressure & $140 / 72$ & $127 / 77$ & $141 / 67$ & $112 / 71$ \\
\hline SpO2 & 99 & 99 & 94 & 98 \\
\hline
\end{tabular}

time variability are associated with poorer health and physical functional status (Brach et al 2008). In addition gait speed, figure-of-eight and four-squarestep-tests proved to be of high reliability in measuring functional outcomes (Peters et al 2012, Whitney et al 2007). The four-square-step-test is also a very effective balance assessment tool in identifying multidirectional movement performance deficits (Whitney et al 2007). The Figure-of-8-Walk-Test correlates with step width variability and fear of falling (Hess et al 2010). The fivetime-sit-to-stand-test (5TSTS) correlates with lower extremity strength, gait and balance (Whitney et al 2005, Brown et al 1995). The baseline measured outcome values (Table 2 ) determined the patients' functional status according to normative values (Hess et al 2010, Guccione et al ).

\section{DIAGNOSES AND PROGNOSIS}

The author classified these patients according to the Guide of Physical Therapy Practice's Pattern 5A. The history of falls, medical history of osteoarthritis and hypertension, foot deformities, poor outcome values on the five-time-sit-to-stand, four-square-step and BESTest tests all confirmed that these patients were at high risk of falling. The patients had a good prognosis to achieve better balance outcomes, improve gait speed with the figure-ofeight and four-square-step tests, and to maintain high functional independence living status with lower risk of repetitive falling episodes. The goal of physical therapy was to decrease the patients' risks of falling by improving their objective balance properties. 
Table 2: Functional tests and outcomes compared to normative values.

\begin{tabular}{|c|c|c|c|}
\hline \multirow[t]{2}{*}{ Tests } & \multicolumn{2}{|c|}{ Outcomes } & \multirow[t]{2}{*}{ Normative values } \\
\hline & Patient A & Patient B & \\
\hline Gait speed & $1.15 \mathrm{~m} / \mathrm{s}$ & $1.15 \mathrm{~m} / \mathrm{s}$ & Physical Independant \\
\hline Figure of 8 test & $8.12 \mathrm{sec}$ & $10.37 \mathrm{sec}$ & Normal \\
\hline 5TSTS test & $15.31 \mathrm{sec}$ & $11.47 \mathrm{sec}$ & $\begin{array}{c}\text { Frail > 15sec } \\
\text { (Hess et al 2010) }\end{array}$ \\
\hline Four square step test & $19.59 \mathrm{sec}$ & $20.00 \mathrm{sec}$ & Frail \\
\hline BESTtest & $62 \%$ & $67 \%$ & No normative values \\
\hline - Biomechanical constrains & $53 \%$ & $53 \%$ & Poor \\
\hline - Stability limits/vertically & $86 \%$ & $85 \%$ & Good \\
\hline $\begin{array}{ll}\text { - } & \text { Anticipatory } \\
\text { postural adjustments }\end{array}$ & $50 \%$ & $50 \%$ & Poor \\
\hline - $\quad$ Postural responses & $67 \%$ & $78 \%$ & Fair \\
\hline - Sensory orientation & $60 \%$ & $80 \%$ & A: Fair, B: Poor \\
\hline - $\quad$ Stability in gait & $48 \%$ & $52 \%$ & Poor \\
\hline
\end{tabular}

\section{INTERVENTION}

\section{Exercise prescription}

Patients A and B target exercise heart rate was monitored to maintain $60 \%$ of their maximum HR. Patient A's reduced exercise tolerance and heart rate secondary to the beta blockers was assessed with the use of the rateof-perceived-exertion (RPE) scale at $13-15 / 20$. The one repetition maximum weight for the Theraband $\AA$ was calculated at $70 \%$ and progressed by $5 \%$ with good muscle tolerance at twelve repetitions. The patients received therapy three times a week for 30 to 45 minutes. The exercise programs were conducted in twelve treatments over a four week period according to the Guide to Physical Therapy Practice.

\section{Exercise progression}

Both patients were instructed in transverse abdominus muscle activation at initial treatment and received the same biomechanical postural correction education, static (figure 1), and dynamic (figure 2) balance exercise regime during therapy. They performed their exercises in front of a mirror for optimal corticospinal activation (Funasa et al, 2007). Patient B received balance training, with additional lumbar stabilization training which reinforced the external focus motor learning principle with the use of a biofeedback device (Schmith et al 2011) (Appendix 1). The biofeedback device was inflated to 40. Co-contraction of the transverse abdominus muscle was facilitated with inflation to 50 while doing extremity movements in standing position. The static and dynamic balance exercises were performed at random practice on a variety of different standing surfaces to incorporate environmental fluctuation and to optimize attention, executive function and retention (Schmith et al 2011). The patients' balance positions varied constantly by changing movement direction; progressing from forward lunges to side lunges and adding bilateral (D1) upper extremity proprioceptive neuromuscular facilitation (PNF) Theraband $\AA$ pattern exercises. Static tandem stance position was progressed to tandem walking and forward lunges to side lunges after two weeks.

\section{RESULTS}

The patients were re-assessed after two and four weeks (Table 3). The statistical significance within each patient's outcome values in Table 4 were calculated with the use of the student-t test (Table 4). The paired t-test was used to calculate the $95 \%$ confidence intervals, mean and standard deviation and the two tailed p-value difference between the two patients. The single $p$-value statistical difference between the patients was calculated with the Friedman test and Chi square approximation.

Both patients showed statistically significant improvements in all the outcome values except in vertical stability limits (Table 4). Patient A, who performed isolated balance training exercises, showed no improvement in vertical stability outcome values which emphasizes the value of additional lumbar stabilization exercises during balance training. Patient $\mathrm{B}$ with the additional lumbar stabilization exercises showed greater improvements in gait speed (9\%) and stability in gait (20\%). Patient B also improved at a faster rate after two weeks of treatment with the 5TSTS test's scores.

Statistical significance equal improvements were found in Patient $\mathrm{A}$ and Bs' figure-of-eight test, four-squarestep tests, biomechanical constraints, anticipatory postural adjustments, postural responses and sensory orientation. 


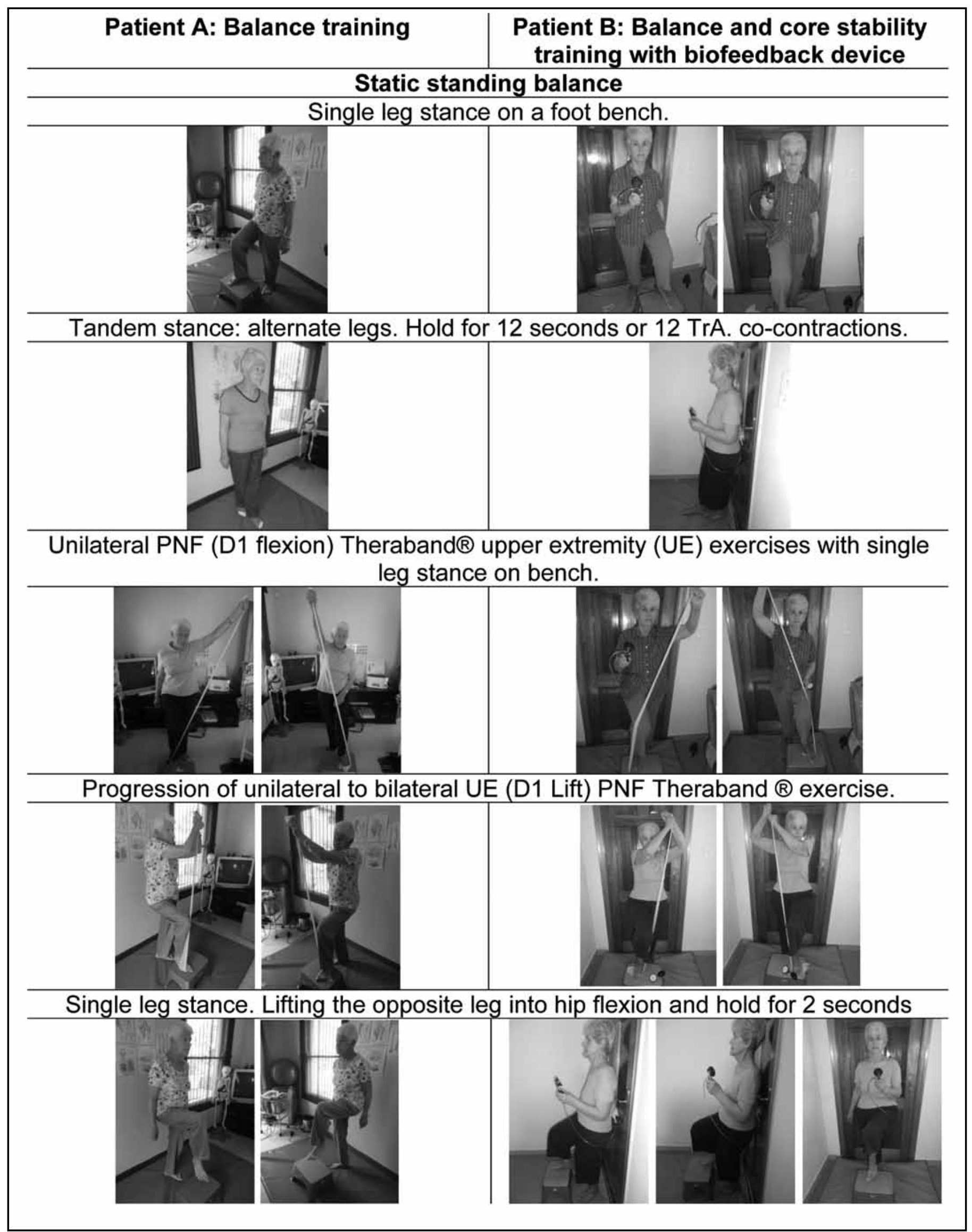

Figure 1: Static balance exercises of Patient A and balance exercise incorporated with lumbar stabilization with a biofeedback device of Patient B 


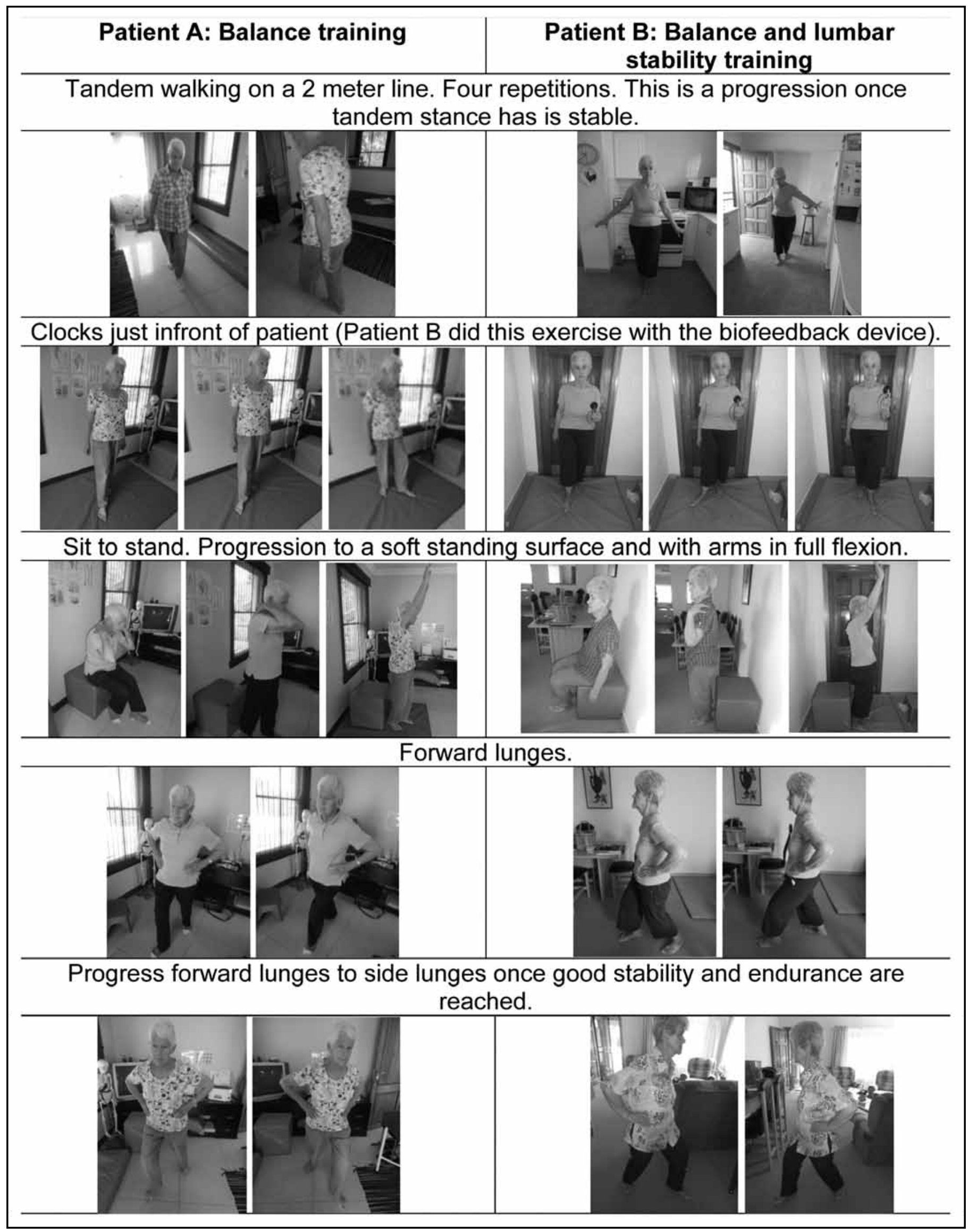

Figure 2: Dynamic functional balance exercises 
The anticipatory postural adjustments and sensory orientation outcome values showed a ceiling effect after two weeks.

\section{DISCUSSION}

Statistically significant improvements in the functional assessment tests' results showed the evidence-based effect of balance exercises. The equal improvement of figure-of-eight and four-square-step tests, biomechanical constrains, anticipatory postural adjustments, postural responses and sensory orientation correlated with other high quality evidence based studies (Madureira et al 2007, Burke et al 2010). Balance exercises rather than additional lumbar stabilization significantly improved the patients' anticipatory postural adjustments ability. Balance training also can improve patients' ability to change position in multiple directions without any activation of the lumbar stabilizers (Nagai et al 2012). Anticipatory postural adjustments are considered the major "line of defence" against self-inflicted postural perturbations. Postural stability, body protection and focal movement performance during anticipatory postural adjustments are maintained by the central nervous system (Yiou et al 2012). The equal improvements in the biomechanical constraints, figure-eight and four-step-square tests results in this study correlated with the anticipatory postural adjustments' ability to adapt to various constraints like biomechanical constraints, postural stability, task superimposition, physiological fatigue, temporal time pressure and psychological fear of falling (Yiou et al 2012).

Table 3: Results of functional assessments of Patient A and Patient B at baseline, after two weeks- and after four weeks of treatment.

\begin{tabular}{|c|c|c|c|c|c|c|}
\hline Outcome measures & \multicolumn{2}{|c|}{ Baseline } & \multicolumn{2}{c|}{ Two weeks } & \multicolumn{2}{c|}{ Four weeks } \\
\hline Patient & A & B & A & B & B \\
\hline Gait speed & $1.15 \mathrm{~m} / \mathrm{s}$ & $1.15 \mathrm{~m} / \mathrm{s}$ & $1.16 \mathrm{~m} / \mathrm{s}$ & $1.24 \mathrm{~m} / \mathrm{s}$ & $1.19 \mathrm{~m} / \mathrm{s}$ & $1.29 \mathrm{~m} / \mathrm{s}$ \\
\hline Figure of 8 test & $8.12 \mathrm{sec}$ & $10.37 \mathrm{sec}$ & $7.66 \mathrm{sec}$ & $7.75 \mathrm{sec}$ & $6.69 \mathrm{sec}$ & $6.86 \mathrm{sec}$ \\
\hline 5TSTS test & $15.31 \mathrm{sec}$ & $11.47 \mathrm{sec}$ & $11.34 \mathrm{sec}$ & $7.22 \mathrm{sec}$ & $10.35 \mathrm{sec}$ & $7.20 \mathrm{sec}$ \\
\hline Four square step test & $19.59 \mathrm{sec}$ & $20.00 \mathrm{sec}$ & $13.66 \mathrm{sec}$ & $10.54 \mathrm{sec}$ & $12.81 \mathrm{sec}$ & $9.28 \mathrm{sec}$ \\
\hline BESTest & $62 \%$ & $67 \%$ & $75 \%$ & $83 \%$ & $80 \%$ & $91 \%$ \\
\hline Biomechanical constrains & $53 \%$ & $53 \%$ & $53 \%$ & $53 \%$ & $67 \%$ & $67 \%$ \\
\hline Stability limits/vertically & $86 \%$ & $85 \%$ & $86 \%$ & $100 \%$ & $86 \%$ & $100 \%$ \\
\hline Anticipatory postural adjustments & $50 \%$ & $50 \%$ & $67 \%$ & $67 \%$ & $67 \%$ & $72 \%$ \\
\hline Postural responses & $67 \%$ & $78 \%$ & $72 \%$ & $87 \%$ & $87 \%$ & $100 \%$ \\
\hline Sensory orientation & $60 \%$ & $80 \%$ & $93 \%$ & $100 \%$ & $93 \%$ & $100 \%$ \\
\hline Stability in gait & $48 \%$ & $52 \%$ & $71 \%$ & $86 \%$ & $76 \%$ & $100 \%$ \\
\hline
\end{tabular}

Table 4: Statistical outcome measures

\begin{tabular}{|c|c|c|c|c|c|c|}
\hline Patient & \multicolumn{2}{|c|}{ Patient A } & \multicolumn{2}{|c|}{ Patient B } & \multicolumn{3}{c|}{ Difference between Patient A and Patient B } \\
\hline Outcome measures & \multicolumn{2}{|c|}{$\mathbf{p}$-value } & 95\% Cl & Mean & SD & p-value \\
\hline Gait speed & 0.0001 & 0.0011 & -0.191 to 0.071 & -0.060 & 0.053 & 0.1573 \\
\hline Figure of 8 test & 0.0032 & 0.0156 & -3.879 to 2.205 & -0.837 & 1.225 & 0.0833 \\
\hline 5TSTS test & 0.0148 & 0.0260 & 2.263 to 4.943 & 3.703 & 0.499 & 0.0833 \\
\hline Four square step test & 0.0148 & 0.0260 & -3.301 to 7.461 & 2.080 & 2.166 & 0.5637 \\
\hline BESTtest & 0.0055 & 0.0076 & -20.5 to 7.8 & -6.3 & 5.7 & 0.1573 \\
\hline Stability limits/vertically & - & 0.0028 & -30.5 to 12.5 & -9.0 & 8.7 & 0.5637 \\
\hline Anticipatory postural adjustments & 0.0084 & 0.0110 & -8.8 to 5.5 & -1.7 & 2.9 & 0.3173 \\
\hline Postural responses & 0.0063 & 0.0052 & -18.0 to -8.0 & -13.0 & 2.0 & 0.0833 \\
\hline Sensory orientation & 0.0175 & 0.0051 & -34.3 to 3.0 & -15.7 & 7.5 & 0.0833 \\
\hline Stability in gait & 0.0171 & 0.0308 & -39 to 10.5 & -14.3 & 10.0 & 0.0833 \\
\hline
\end{tabular}




\section{Lumbar stabilization exercises.}

Similar to other lumbar stabilization exercise studies, there were significant improvements in the vertical stability limits and gait speed with intervention aimed at stabilizing the lumbar spine through the contraction of the transverse abdominus muscles (Freeman et al 2012). The improvement of gait speed and stability correlated with Hodges et al 1997 conclusion that transverse abdominus activates prior to the initiation of all extremity movements. The timing between trunk and pelvic rotations and erector spinae activity varies systematically with walking velocity and any alteration is reflected in spinal stabilization during unexpected perturbations (Lamoth et al 2007). Lumbar stabilization exercises causes significant improvements in disability scores and ground reaction forces, due to improved changes in load transfer patterns during perturbation (Muthukrishnan et al 2010). Phasic superficial paraspinal activity is associated with foot strike which controls trunk motion in the frontal and sagittal planes during locomotion. The tonic activation of the transverse abdominus muscle throughout the gait cycle provides constant intersegmental stiffness and is the first line of defence against the cyclic internal and external lumbo-pelvic forces associated with gait (Saunders 2007).

Balance is also controlled through the temporal relationship between trunk and lower extremity strength (Yen et al 2011). The improved five-times-sit-to-stand test results showed that the additional lumbar stabilization exercises had an impact on lower extremity strength. The significant relationship which exists between knee extension force and gait speed correlate with this study's results (Brown et al 1995). Afferent input from the hip joints' load receptors play a crucial role in the generation of locomotion activity in the human spinal cord during loading phase (Dietz et al 2002). The use of body weight and control is especially important to facilitate the activity and load input in the extensor muscles (MacKay-Lyons 2002). It is hypothesized that the lumbar stabilizers might play a role in facilitating activity of the lower extremity extensor muscles due to prior activation and feed forward of the transverse abdominus muscle during gait initiation. The additional lumbar stabilization exercises during balance exercises showed that it may potentially add value to the patient's functional outcome. Future randomized control trials are recommended with a larger sample size of frail older adult population.

\section{CONCLUSION}

The additional lumbar stability training during balance training has the potential to improve vertical stability, gait speed and gait stability at an earlier stage of treatment than just plain balance training alone. The improved five-time-sit-tostand test values also showed that higher physical independence levels can be reach sooner.

\section{REFERENCES}

Brach J S, Perera S, Studenski S, Newman A B. The Reliability and Validity of Measures of Gait Variability in Community-Dwelling Older Adults. Arch Phys Med Rehabil. 2008. December; 89 (12): 2293-2296.

Brown M, Sinacore D, Host H. The relationship of strength to function in the older adult. J Gerontology. 1995.;50A(special issue):55-59.

Burke T N, Franca F J, Ferreira de Meneses S R, Cardoso V I, Marques A P. Postural control in elderly persons with osteoporosis: Efficacy of an intervention program to improve balance and muscle strength: a randomized controlled trail. Am J Phys Med Rehabil. 2010. Jul, 89 (7): 549-56

Center of Disease Control and Prevention. Older Adult Falls Data \& Statistics: Cost of falls. Injuries in Older Persons in the United States, 2005. http:// www.cdc.gov/homeandrecreationalsafety/Falls/ data.html

Czerniewicz S, Nicholson C M. Hale and hearty. The benefits of exercises in the elderly. CME Nov/ Dec. 2004. Vol 22, 11.

Dietz V, Müller R, Colombo G. Locomotor activity in spinal man: significance of afferent input from joint and load receptors. Brain 2002. 125, 2626-2634

Freeman JA, Gear M, Pauli A, Cowan P, Finnigan C, Hunter H, Mobberley C, Nook A, Sims R, Thain J. The effect of core stability training on balance and mobility in ambulant individuals with multiple sclerosis: a multi-center series of single case studies. Mult Scler. 2010. Nov, 16 (11): 1377-84

Funasa K, Tabira T, Higashi T, Liang N, Kasai T. Increased corticospinal excitability during direct observation of self-movement and indirect observation with a mirror box. Neuroscience Letters 419 (2007). 108-112.

Guccione A A, Wong R A, Avers D. Geriatric Physical Therapy. Third edition. Elsevier Mosby

Guide to Physical Therapy Practice. Second edition. Revised 2003. American Physical Therapy Association

Hess RJ, Brach JS, Piva SR, VanSwearingen JM. Walking skill can be assessed in older adults: validity of the Figure-of- 8 Walk Test. Physical Therapy. 2010. Jan; 90(1):89-99.

Hodges P W, Richardson C. Contraction of the abdominal muscles associated with movement of the lower limb. Phys Ther, 1997., 77: 132-142

Kaya DO, Ergun N, Hayran M. Effects of different segmental spinal stabilization exercise protocols on postural stability in asymptomatic subjects: randomized controlled trial. J Back Musculoskelet Rehabil. 2012. ;25(2):109-16

Lamoth CJ, Daffertshofer A, Meijer OG, Beek PJ. How do persons with chronic low back pain speed up and slow down? Trunk-pelvis coordination and lumbar erector spinae activity during gait. Gait Posture. 2006. Feb;23(2):230

Leddy AL, Crowner BE, Earhart GM. Functional gait assessment and balance evaluation system test: reliability, validity, sensitivity, and specificity for identifying individuals with Parkinson disease who fall. Physical Therapy. 2011 Jan;91(1):102-13

Li F, Harmer P, Fitzgerald K, Eckstrom E, Stock R, Galver J, Maddalozzo G, Batya S. Tia Chi and postural stability in patients with Parkinson's Disease. N Engl J Med 2010. Feb 9, 366(6) 511-519

MacKay-Lyons. Central Pattern generation of locomotion: A review of the evidence. Physical Therapy. 82 (1), January 2002

Madureira MM, Takayama L, Gallinaro AL, Caparbo VF, Costa RA, Pereira RM. Balance training program is highly effective in improving functional status and reducing the risk of falls in elderly women with osteoporosis: a randomized controlled trial. Osteoporos Int. 2007. Apr;18(4):419-25

Muthukrishnan R, Shenoy S D, Jaspal SS, Nellikunja S, Fernandes S. The differential effects of core stabilization exercise regime and conventional physiotherapy regime on postural control parameters during perturbation in patients with movement and control impairment chronic low back pain. Sports Medicine, Arthroscopy, Rehabilitation, Therapy and Technology. 2010., 2:13

Nagai K, Yamada M, Tanaka B, Uemura K, Mori S, Aoyama T, Ichihashi N, Tsuboyama T. Effects of balance training on muscle coactivation during postural control in older adults: a randomized controlled trial. J Gerontol A Biol Sci Med Sci. 2012. Aug;67(8):882-9 
O'Sullivan P B. Lumbar segmental 'instability': clinical presentation and specific stabilizing exercise management. Manual therapy, 2000., 5 (1), 2-12

Orr R. Contribution of muscle weakness to postural instability in the elderly. A systematic review. Eur J Phys Rehabil Med 2010. Jun 46 (2): 183-220

Peters DM, Fritz SL, Krotish DE. Assessing the Reliability and Validity of a Shorter Walk Test Compared With the 10-Meter Walk Test for Measurements of Gait Speed in Healthy, Older Adults. J Geriatric Physical Therapy. 2012. Mar 11 Saunders S. Core stability and exercise prescription. A research update: implications for physiotherapist. The Australian Sports Physiotherapy Magazine, 2007.

Schmith R A, Lee T A. Motor Control and Learning. A behavioral emphasis. Fifth edition. 2011. Human kinetics

Sherrington C, Whitney JC, Lord SR, Herbert RD, Cumming RG, Close JC. Effective exercise for the prevention of falls: a systematic review and meta-analysis. J Am Geriatr Soc. 2008. Dec; 56(12):2234-43.

\section{APPENDIXES}

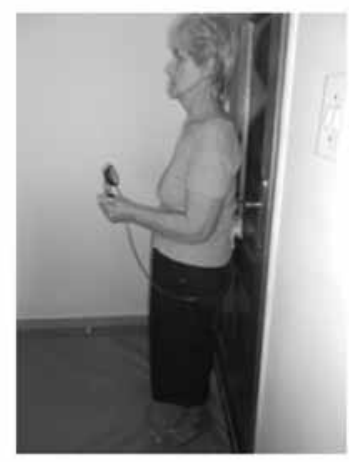

APPENDIX 1: Biofeedback (Stabilizer) device behind patient's back. 12 repetition TrA contractions
Statistics South Africa 2001. Stages in the life cycle of South Africans. http://www.statssa.gov.za/ publications/C2001Stages/C2001Stages.pdf

Summary of the updated American Geriatrics Society/ British Geriatrics Clinical Practice Guideline for Prevention of Falls in Older Persons. Journal of American Geriatric Society, 59: 148$157,2011$.

Whitney SL, Marchetti GF, Morris LO, Sparto PJ. The reliability and validity of the Four Square Step Test for people with balance deficits secondary to a vestibular disorder. Arch Phys Med Rehabil. 2007. Jan;88(1):99-104

Whitney SL, Wrisley DM, Marchetti GF, Gee MA, Redfern MS, Furman JM. Clinical measurement of sit-to-stand performance in people with balance disorders: validity of data for the Five-TimesSit-to-Stand Test. Phys Ther. 2005. Oct; 85(10): 1034-45.

Yen S C, Ling W, Magil R, McDonough A, Gutierrez G M. temporal relationship between trunk and thigh contributes to balance control in load carriage walking. Gait Posture 2011. Jul 34 (3) $402-8$
Yiou E, Caderby T, Hussein T. Adaptability of anticipatory postural adjustments associated with voluntary movement. World J Orthop. 2012. June 18; 3(6): 75-86. 